\title{
A complicated case of von Hippel-Lindau disease
}

\author{
G Thomas, R Hillson
}

Answers on p 481.

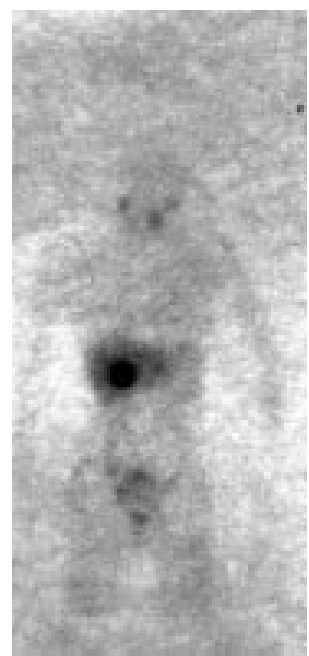

Figure 3 MIBG isotope uptake scan.

\section{Department of Diabetes and Endocrinology, Hillingdon Hospital, Uxbridge, Middlesex, UK \\ G Thomas \\ R Hillson}

Correspondence to: Dr G Thomas, Flat 1, 134 Shirland Road, Maida Vale, London W9 2BT, UK gthomas_uk@hotmail.com

Submitted 2 September 1999 Accepted 4 April 2000
A 17 year old female shop assistant presented with a three week history of generalised headache, associated with nausea, vomiting, and vertigo. She had no past medical history, and was taking no regular medication. Her mother was currently receiving radiotherapy for anaplastic carcinoma of the thyroid gland. On examination she had an ataxic gait, bilateral papilloedema, and horizontal nystagmus to right lateral gaze. Left sided dysdiadokinesis and hyper-reflexia were demonstrated. Power and sensation were preserved. Computed tomography of the brain revealed a cystic lesion within the left cerebellum. Subsequent magnetic resonance imaging (MRI) revealed a second, non-cystic lesion within the region of the right vermis (fig 1). Both images were consistent with cerebellar haemangioblastomata. A posterior fossa craniotomy was performed, with successful excision of both tumours. She made an uneventful recovery, with complete resolution of all symptoms, and was subsequently discharged.

During a follow up outpatient appointment six months later, she complained of frequent panic attacks, associated with sweating and palpitation that had begun two months earlier. These episodes were precipitated by exercise or excitement. She gave no history of heat intolerance, weight loss, or diarrhoea. Examination was entirely normal. Abdominal computed tomography (fig 2), and subsequent $\mathrm{I}^{131}$ metaiodobenzylguanidine (MIBG) isotope uptake scan (fig 3) are shown here.

\section{Questions}

(1) What family history should be explored in a 17 year old girl with multiple cerebellar haemangioblastomas and why?

(2) What is the nature of the current problem and unifying diagnosis?

(3) What other complications occur in this disease?

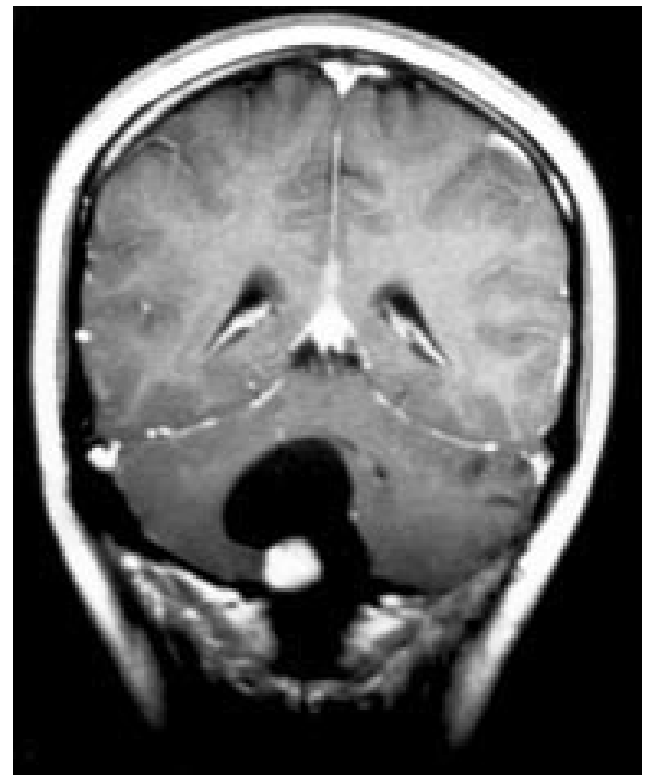

Figure 1 MRI of the brain.

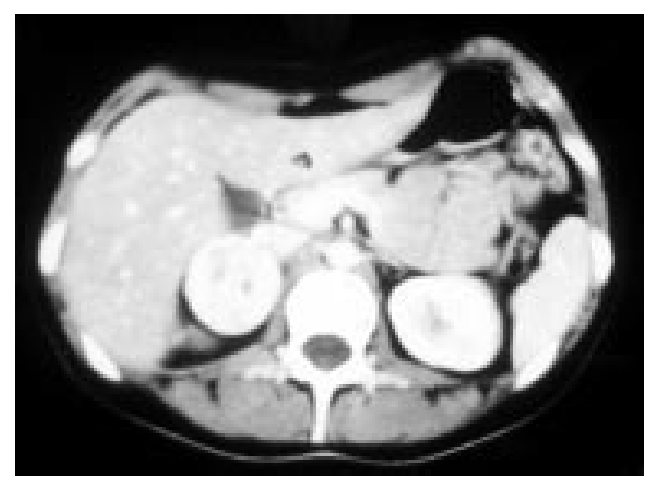

Figure 2 Computed tomography of the abdomen.

(4) What is the significance of thyroid cancer in the mother? 
Answers on p 481.

University Department of Geriatric Medicine,

North Staffs Combined Health Care NHS Trust, City General Hospital, Stoke-on-Trent, UK S A M Saeed

Queen Elizabeth

Medical Centre and

Walsall Manor

Hospital, Walsall, West

Midlands, UK

D Francis

R Brooks

Correspondence to: Dr Saad A M Saeed, Springfield Unit, City General Hospital,

Stoke-on-Trent, Staffs ST4 6QG, UK

ST4 6QG, UK
saad_saeed@hotmail.com

Submitted 24 January 2000 Accepted 6 March 2000
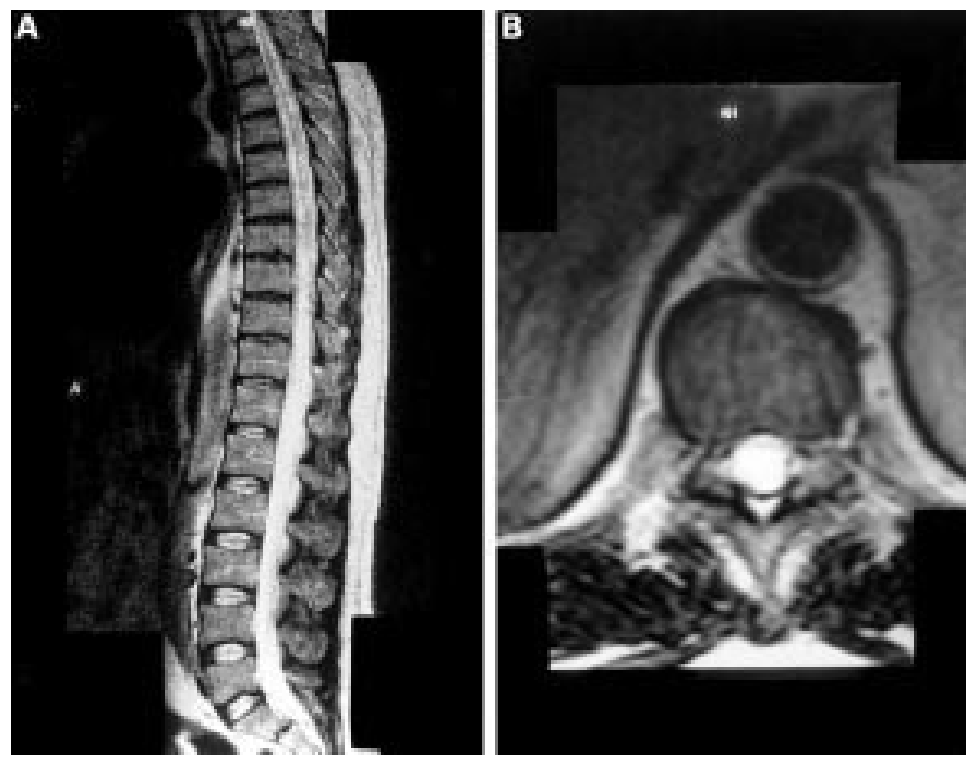

Figure 1 (A) Axial and (B) sagittal MRI. T2 weighted scan of the spinal cord.

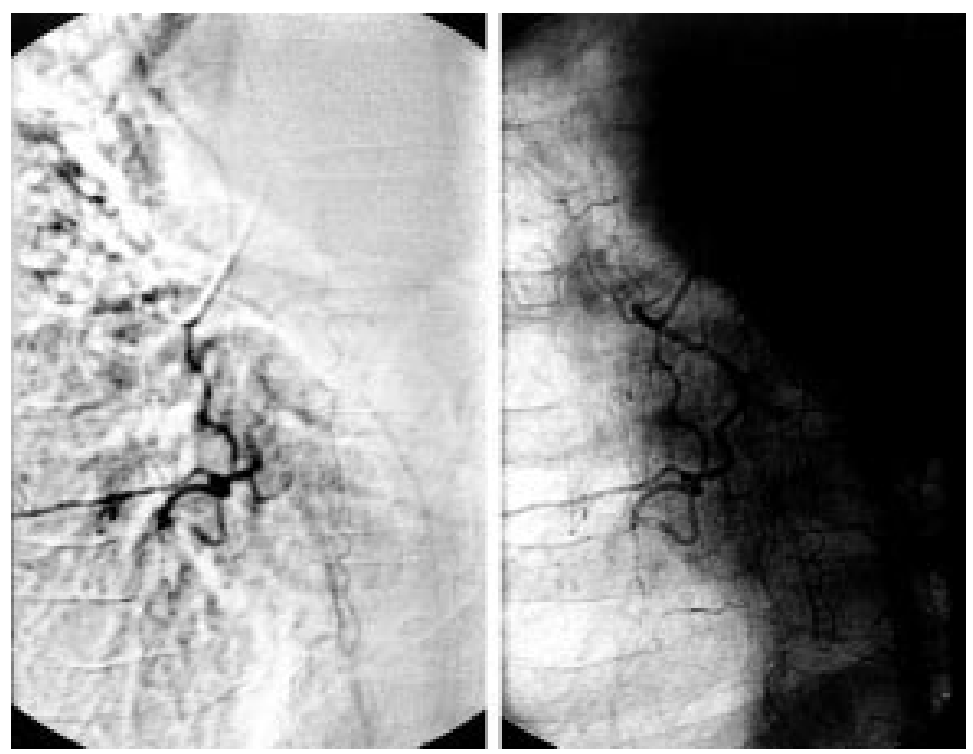

Figure 2 Spinal angiogram. Two pictures of the anterioposterior view.

\author{
S A M Saeed, D Francis, R Brooks
}

A 56 year old machine operator presented with mild weakness and sensory disturbance in his lower limbs after he woke up from an arthroscopy operation. At the time he did not seek medical attention. His symptoms progressed over the next four months to the degree that he was unable to stand and he developed back pain radiating to the legs, urinary frequency, hesitancy, and incontinence of urine. There was no history of claudication in the legs. $\mathrm{He}$ was a heavy smoker and suffered from ischaemic heart disease and type 2 diabetes mellitus.

On examination he was overweight. Straight leg raising test was within normal limits.

\section{An unusual cause of paraplegia}

Neurological examination showed normal cranial nerves and normal upper limbs. Lower limb examination revealed grade $3 / 4$ proximal limb weakness with absent ankle jerks and equivocal plantar responses. Light touch and pinprick sensation was impaired in L1-S3 distribution bilaterally with impaired vibration. Coordination was normal. The remaining physical examination was otherwise unremarkable.

Laboratory examination showed high inflammatory parameters with an erythrocyte sedimentation rate of $33 \mathrm{~mm}$ in the first hour and a $\mathrm{C}$ reactive protein of $68 \mathrm{mg} / \mathrm{l}$. The following tests were either normal or negative: full blood count, biochemistry profile, immunoglobulins, serum vitamin B12, serum and red blood cell folate, vasculitis, thrombophelia, and paraneoplastic screens, angiotensin converting enzyme level, and Treponema pallidum haemagglutination test.

Lumbar puncture showed a cerebrospinal fluid (CSF) opening pressure of $260 \mathrm{~mm}$ with high CSF protein at $1.9 \mathrm{~g} / 1$ (normal $0.1-0.4$ ) with no evidence of oligoclonal band. CSF glucose $5.7 \mathrm{mmol} / 1$ (blood glucose $10.4 \mathrm{mmol} / \mathrm{l}$ ), 73 red cells/high power field and no leucocytes or abnormal cells on cytospin. There was no evidence of xanthochromia.

Computed tomography and magnetic resonance imaging (MRI) scans of the brain were normal; however, an MRI scan of the spinal cord was abnormal (fig 1).

After he was given specific medical treatment he became paraplegic (leg power 0/4) and lost bladder sensation. An urgent spinal angiogram confirmed the diagnosis (fig 2).

$\mathrm{He}$ had specific interventional treatment after which he had some improvement in sensation in the lower limbs, only to be replaced by unpleasant dysthesia, but he started passing urine normally. Lower limb strength improved to grade $2-3 / 4$, although he was not weight bearing.

Eight months after the initial presentation he continued to improve, although he required a wheelchair for mobility.

\section{Questions}

(1) What differential clinical diagnoses would you consider?

(2) What do the spinal MRI scans show?

(3) What was the first treatment given which was followed by paraplegia?

(4) What is the pathological abnormality suggested by the spinal angiogram?

(5) What specific treatment did the patient receive? 


\title{
Palpable breast mass in a lactating woman
}

\author{
M Goyal, T B Poulton, O Konez
}

Answers on $p 482$.

Department of

Radiology, Aultman

Hospital, 2600 Sixth

Street, SW, Canton,

Ohio 44710, USA

M Goyal

T B Poulton

O Konez

Correspondence to:

Dr Poulton

chestimagr@aol.com

Submitted 26 April 2000 Accepted 9 May 2000

Answers on $p 483$.

\section{A patient with severe hyperphosphataemia}

Department of

Medicine and

Therapeutics, The

Chinese University of

Hong Kong, Prince of

Wales Hospital, New

Territories, Hong Kong

K M Chow

P K T Li

Correspondence to:

Dr Philip K T Li,

Department of Medicine and

Therapeutics, The Chinese

University of Hong Kong,

Prince of Wales Hospital,

Shatin, Hong Kong

philipli@cuhk.edu.hk

Submitted 22 February 2000 Accepted 3 April 2000
A 35 year old woman noted a painless lump in her right breast during self examination. She was three months postpartum and had been breast feeding her daughter since birth. Her past medical history included three previous uneventful pregnancies, each followed by an uncomplicated period of breast feeding. She had no other significant illnesses in the past. Her mother had died of postmenopausal breast cancer. She had never been on oral contraceptives.

On examination, there was a mobile, nontender, firm palpable mass of about $3 \mathrm{~cm}$ in the upper outer quadrant of the right breast, close to the nipple. There was no swelling or erythema of the overlying skin. Although the clinical impression favoured a benign breast mass, breast cancer was also considered.

High resolution ultrasound of the right breast revealed a solid, predominantly hypoechoic mass with somewhat heterogeneous echotexture. Some of the margins of the mass were indistinct causing it to blend with the surrounding breast parenchyma. The mass was ovoid, width greater than height, and there was considerable posterior acoustic enhancement. There was no evidence of calcifications and the overlying skin and subcutaneous fat were

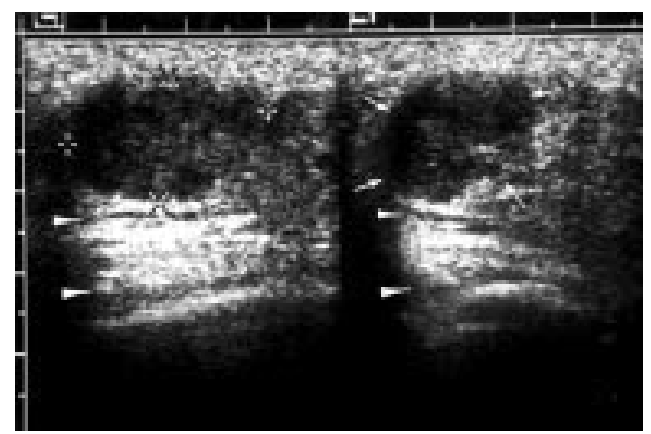

Figure 1 Longitudinal (left, with electronic cursors) and transverse (right, with arrows) ultrasound images of the palpable breast mass showing a solid $2.5 \mathrm{~cm}$ long, ovoid mass with its long axis parallel to the chest wall. Note the considerable posterior acoustic enhancement (arrowheads).

sonographically normal. Transverse and longitudinal ultrasound images of the mass are shown in fig 1 .

\section{Questions}

(1) What is the differential diagnosis of a solid mass in a pregnant or lactating woman?

(2) What further work-up is needed to confirm the diagnosis in this case?

(3) What is the most likely diagnosis of this patient's palpable breast mass?

Table 1 Biochemical investigations

\begin{tabular}{lllll}
\hline Test & Preliminary & $\begin{array}{l}\text { One day after } \\
\text { colonoscopy }\end{array}$ & Six days later & $\begin{array}{l}\text { Reference } \\
\text { ranges }\end{array}$ \\
\hline Potassium $(\mathrm{mmol} / \mathrm{l})$ & 3.06 & 2.8 & 3.4 & $3.5-5.1$ \\
Creatinine $(\mu \mathrm{mol} / \mathrm{l})$ & 700 & 740 & 1130 & $80-140$ \\
Calcium $(\mathrm{mmol} / \mathrm{l})$ & - & 1.02 & 1.47 & $2.20-2.60$ \\
Phosphate $(\mathrm{mmol} / \mathrm{l})$ & - & 8.04 & 3.90 & $0.80-1.40$ \\
\hline
\end{tabular}

investigation revealed significant hyperphosphataemia, as shown in table 1 . Further evaluation confirmed chronic renal failure secondary to polycystic kidney disease.

\section{Questions}

(1) What is the cause of the hyperphosphataemia?

(2) What action would you take?

(3) How should this be avoided? 


\title{
Abnormal behaviour in a man with massive, generalised, peripheral lymphadenopathy
}

\author{
B L Samaga, M V Nagaraj
}

Answers on $p 485$.

Department of Clinical Medicine, Kasturba Medical College, Manipal, Karnataka, India

B L Samaga

M V Nagaraj

Correspondence to: Dr B L Samaga, KMC Qtrs 135, Manipal Udipi, Karnataka, PIN 576119, India

bl_samaga@yahoo.com

Submitted 29 February 2000 Accepted 18 May 2000
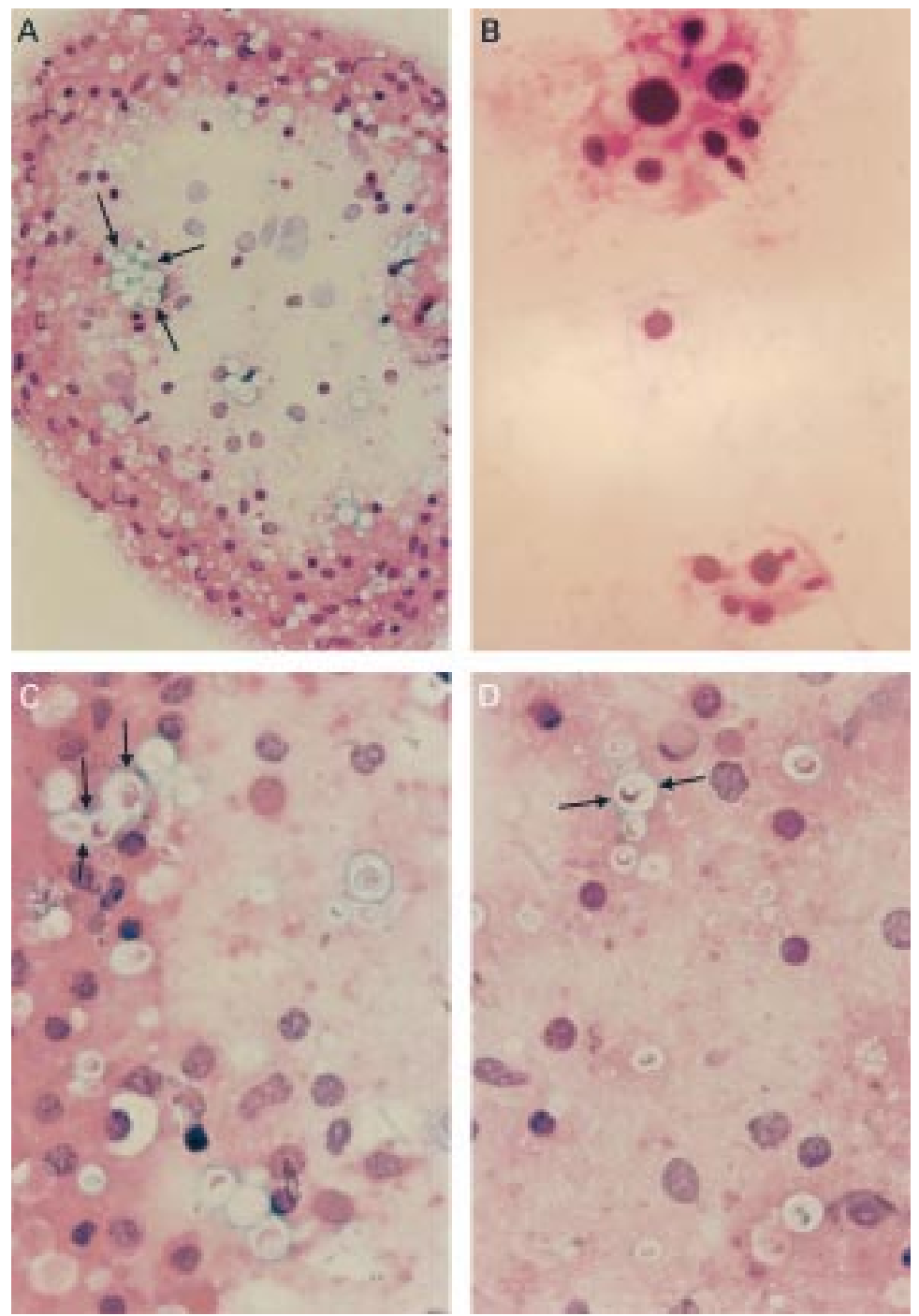

surroundings. Waxing and waning of alertness and attention deficits progressed to deeper levels of drowsiness during the hospital stay. $\mathrm{He}$ was anaemic with mobile, non-tender enlarged lymph nodes $(3-5 \mathrm{~cm})$ in the cervical, axillary, and inguinal areas. There was oropharyngeal candidiasis. His liver was enlarged $3 \mathrm{~cm}$ below the right costal margin; his spleen was just palpable. There were no signs of meningial irritation and no focal neurological deficits.

His haemoglobin concentration was $80 \mathrm{~g} / \mathrm{l}$, leucocyte count $2.3 \times 10^{9} / 1$ with $28 \%$ lymphocytes, CD4 count absent, and erythrocyte sedimentation rate $8 \mathrm{~mm}$ in the first hour. Serum glucose, renal function, electrolytes, calcium, and phosphate were within normal limits. Liver function was abnormal with a threefold rise of alanine aminotransferase (130 $\mathrm{U} / \mathrm{l})$ and aspartate aminotransferase (146 U/1). Alkaline phosphatase was two times the normal level. Serum albumin was $28 \mathrm{~g} / \mathrm{l}$. Induced sputum was negative for acid fast bacilli and Pneumocystis carinii, and for bacterial and fungal growth. Stool was positive for cryptosporidial oocysts. Hepatitis B surface antigen, the Venereal Disease Research Laboratory test, Treponema pallidum haemagglutination, and purified protein derivative test were negative. Electrocardiography, chest radiography, and computed tomography of the brain were normal. Abdominal sonography revealed mild hepatosplenomegaly without focal lesions. Cerebrospinal fluid (CSF) was under normal pressure without pleocytosis and glucose and protein concentrations in the CSF were normal. Fine needle aspiration cytology (FNAC) of the cervical lymph node showed abnormal findings. Microscopic pictures of stained CSF and FNAC samples are shown in fig 1.

\section{Questions}

(1) What are the diagnoses?

(2) What is unusual and atypical in the case illustrated?

Figure 1 Microscopy of stained CSF and FNAC samples. 


\title{
Oligoarthritis in an elderly woman with diarrhoea and weight loss
}

\author{
A L Hepburn, S A Kaye
}

\section{web site \\ extra}

Additional self

appear on the journal's web site

\section{www.postgradmedj.com \\ Department of \\ Rheumatology, \\ Chelsea \& Westminster \\ Hospital, 369 Fulham \\ Road, London \\ SW10 9NH, UK \\ A L Hepburn \\ S A Kaye \\ Correspondence to: Dr Hepburn}

Submitted 13 March 2000 Accepted 3 April 2000 assessment questions

An 80 year old woman was referred in 1995 to the haematology outpatient department with a normocytic anaemia and weight loss. She was found to be deficient in iron, folic acid, and vitamin B12 and was started on replacement treatment. A barium meal and enema were

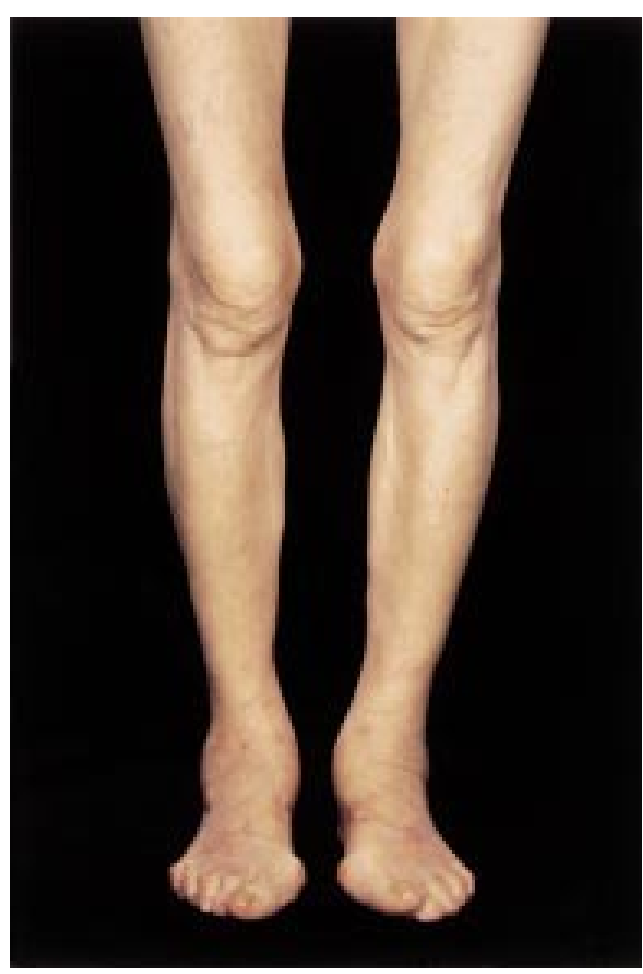

Figure 1 Bilateral ankle swelling and proximal muscle wasting.

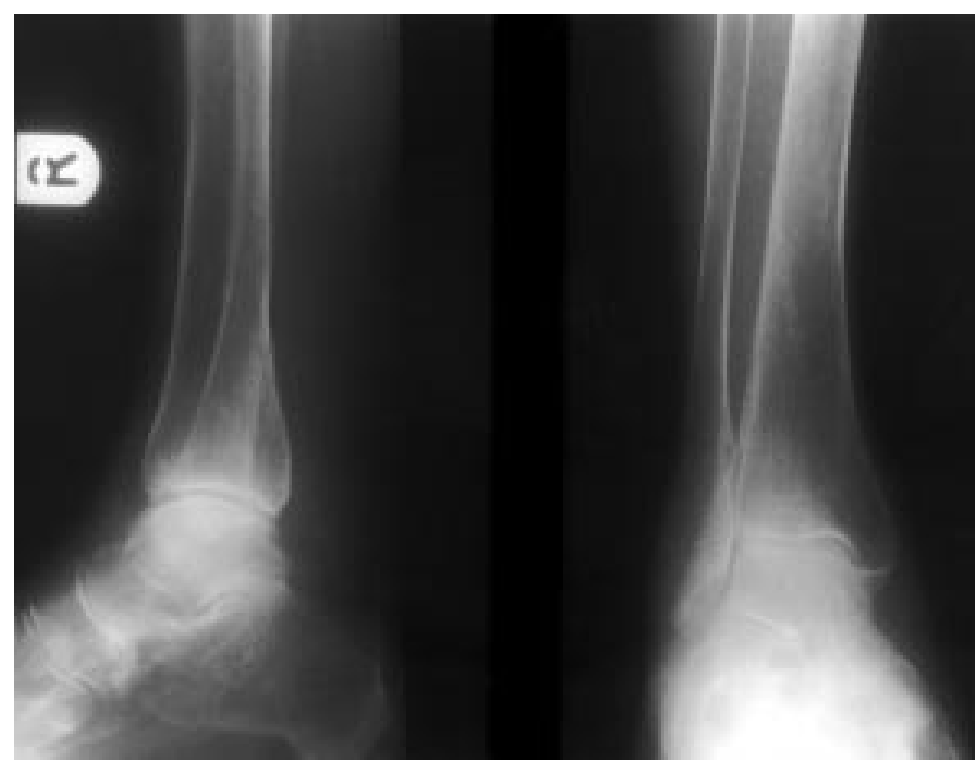

normal and antiparietal cell antibodies negative. In 1997 she fell, fracturing her right proximal ulna and distal humerus. In April 1999 she developed intermittent diarrhoea and lost further weight. There was no rectal bleeding. A sigmoidoscopy, rectal biopsy, and computed tomography pneumocolon were all normal. In September she was referred to the rheumatology outpatient department with a three month history of painful swollen ankles, chest pains, and generalised weakness. Her bowel habit had returned to normal. She continued on folic acid $5 \mathrm{mg} /$ day, hydroxycobalamin $1 \mathrm{mg} / \mathrm{month}$, and ferrous sulphate $375 \mathrm{mg} /$ day, and was taking diclofenac $25 \mathrm{mg}$ twice a day for her pain.

On examination she was cachectic. She was not clinically anaemic and there was no lymphadenopathy. There was a $2 \mathrm{~cm}$ tender liver edge but the remainder of the abdominal examination was normal. Both ankles were swollen and tender (fig 1). There was a fixed flexion deformity and the right elbow and mild weakness of the proximal musculature. There was tenderness of the chest wall, but no muscle tenderness.

Initial investigations showed a haemoglobin of $124 \mathrm{~g} / \mathrm{l}$, mean corpuscular volume $92 \mathrm{fl}$, white cell count $10.4 \times 10^{9} / 1$, and platelets 558 $\times 10^{9} / 1$. The erythrocyte sedimentation rate was $30 \mathrm{~mm} /$ hour and $\mathrm{C}$ reactive protein $1 \mathrm{mg} / \mathrm{l}$. The red cell folate was low at $92 \mu \mathrm{g} / 1$ (normal range 150-700) with a normal vitamin B12 of 254 ng/1 (160-800). Iron studies were normal, as were the serum electrolytes. The adjusted calcium was $1.51 \mathrm{mmol} / \mathrm{l}(2.15-2.65)$ with an albumin of $34 \mathrm{~g} / 1$ (33-47), phosphate 1.2 $\mathrm{mmol} / \mathrm{l}(0.8-1.4)$ and alkaline phosphatase of $323 \mathrm{U} / 1$ (30-130). Her liver function tests, immunoglobulins, and creatine kinase were all normal. Radiographs of both ankles are shown in fig 2. An ultrasound revealed a liver normal in appearance, extending below the costal margin. Dual energy $x$ ray absorptiometry confirmed severe osteoporosis with a $\mathrm{T}$ score at the hip of -3.74 and at the lumbar spine of -5.64 .

\section{Questions}

(1) What is the most likely diagnosis?

(2) What would be the most useful diagnostic test to confirm this?

(3) What is the likely cause of the ankle arthropathy?

(4) Which other arthritides particularly affect the ankle joint? 


\section{Answers}

Q1: What is the most likely diagnosis?

The most likely diagnosis is coeliac disease leading to osteomalacia and osteoporosis. This patient had a serum vitamin $\mathrm{D}$ of $7 \mathrm{nmol} / \mathrm{l}$ (15-100). There was secondary hyperparathyroidism with a serum intact parathyroid hormone of $25.69 \mathrm{pmol} / 1$ (1.05-5.26). She was treated with a single dose of calciferol 300 000U intramuscularly, together with calcium carbonate $1 \mathrm{~g} /$ day and oral cholecalciferol $800 \mathrm{U} /$ day. Her chest wall pain settled rapidly and marked improvement in objective proximal muscle power was seen.

\section{Q2: What would be the most useful diagnostic test to confirm this?}

The most useful diagnostic test would be duodenal or jejunal biopsy. The biopsy showed total villous atrophy, crypt hyperplasia, and an intraepithelial infiltrate of lymphocytes (fig 3). Her antigliadin antibodies were strongly positive (IgA 81 reference units (RU)/1, normal <25; IgG $200 \mathrm{RU} / 1$, normal <25), although her antiendomysial antibodies were negative.

\section{Q3: What is the likely cause of the ankle arthropathy?}

The most likely cause is coeliac associated oligoarthritis. Ankle radiographs showed osteopenia only. The patient was started on a gluten-free diet and her ankle pain and swelling settled after two months. Her serum calcium, vitamin $\mathrm{D}$, and red cell folate are all now within the normal range and the titres of the antigliadin antibodies have fallen, suggesting compliance with the diet. She has gained some weight. No other joints have become painful.

\section{Q4: Which other arthritides particularly affect the ankle joint?}

Arthritides with a predilection for the ankle include sarcoidosis, rheumatoid arthritis, juvenile chronic arthritis (both pauciarticular onset and systemic onset disease), and gout (box 1).

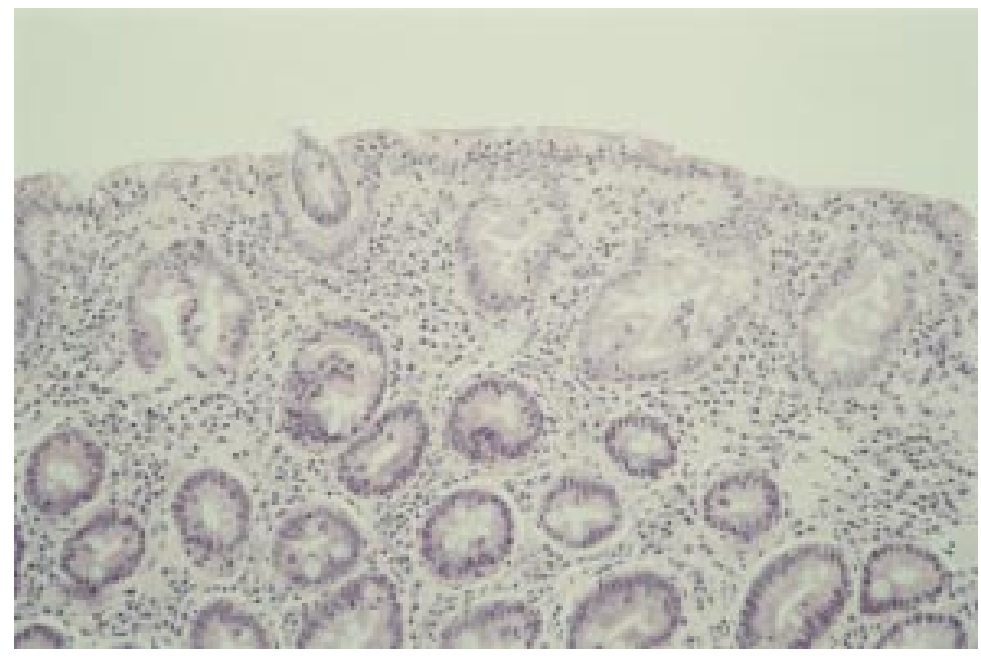

Figure 3 Duodenal biopsy showing total villous atrophy and an intraepithelial infiltrate of lymphocytes.
Box 1: Arthritides commonly affecting the ankle

- Erythema nodosum.

- Sarcoidosis.

- Gout.

- Rheumatoid arthritis.

- Juvenile chronic arthritis.

- Arthritis associated with inflammatory bowel disease.

- Septic arthritis.

- Secondary osteoarthritis.

\section{Discussion}

Coeliac disease has an incidence in England of about $1: 1500 .^{1}$ This appears to be increasing with a shift toward an older age at diagnosis. In adults women are affected twice as frequently as men and tend to present a decade earlier, with a peak incidence in the fourth and fifth decades. Presentation beyond the age of 70 is rare. Gastrointestinal symptoms usually dominate the clinical picture, but up to $50 \%$ of adults have a normal bowel habit at diagnosis. As many as 20\% of adults with coeliac disease may present with one of its musculoskeletal complications (box 2), the most common being metabolic bone disease. ${ }^{2}$ Generalised arthralgia is another common feature, and this may be present for several years before the diagnosis is made. ${ }^{3}$ Fatigue and muscle weakness may be profound, due in part to hypokalaemia seen in patients with chronic diarrhoea. Clubbing is seen in $15 \%$ of untreated patients, but it is not usually associated with the underlying risk of $\mathrm{T}$ cell lymphoma.

A metabolic osteopathy may be the only feature in some patients with coeliac disease. Bony pain and tenderness (particularly of the ribs, lumbar spine and pelvis) is the most common clinical manifestation. ${ }^{4}$ A proximal myopathy typical of osteomalacia may also be seen, but pathological fracture is uncommon. In a study of 17 adult patients with untreated coeliac disease, 16 had a bone mineral density in the osteoporotic range. ${ }^{5}$ The osteopathy is thought to develop as a result of defective calcium transport by the diseased small intestine and impaired vitamin D absorption. Binding of intraluminal calcium and magnesium to unabsorbed dietary fatty acids may also contribute and as a result of these processes secondary hyperparathyroidism may develop, leading to

Box 2: Musculoskeletal manifestations of coeliac disease

- Generalised arthralgia.

- Muscle weakness and fatigue.

- Metabolic bone disease: osteomalacia and/or osteoporosis.

- Clubbing.

- Muscle cramps and tetany.

- Coeliac associated arthropathy: peripheral oligoarthritis and/or axial disease with sacroileitis.

- Associated autoimmune rheumatic disease-for example, primary Sjogren's syndrome. 
calcium mobilisation from bone. Treatment consists of oral calcium supplementation, equivalent to 2-3 g of elemental calcium per day, together with oral vitamin $\mathrm{D}$. The serum calcium and vitamin $\mathrm{D}$ response should be closely monitored. The effect of a gluten-free diet alone on bone density varies. Some studies have shown that it has little impact on preventing further bone loss ${ }^{5}$ while others have shown some benefit. ${ }^{6}$

Adelizzi et al were the first to note an association between coeliac disease and arthritis. ${ }^{7}$ They reported a 28 year old man with a non-erosive, asymmetrical seronegative oligoarthritis affecting his knees and ankles that resolved after the institution of a gluten-free diet. Later, a series of six patients with coeliac disease in whom arthritis was prominent at presentation was described. ${ }^{3}$ In this group, age range $20-60$, arthralgia predated the diagnosis of coeliac disease by up to three years. Three patients also had osteomalacia and two a proximal myopathy. Only three patients had gastrointestinal symptoms, but all had a low serum folate. The joints most commonly affected were the shoulders, hips, knees, and ankles. The arthritis in five patients responded to a withdrawal of gluten from the diet, total remission occurring in three within three months.

The arthritis of coeliac disease is usually non-erosive and self limiting, but progressive erosive disease can occur. In a case similar to ours, a 42 year old woman presented with a one year history of ankle pain and was found to be anaemic with a low serum iron, vitamin B12, and folate. ${ }^{8}$ Osteopenia and soft tissue swelling were seen on the initial radiographs but she later developed erosions in the tarsus that progressed despite a gluten-free diet. In a larger case-controlled study of 200 patients with established coeliac disease, arthritis was found in $26 \% .^{9}$ Of these $36 \%$ had a recurrent asymmetrical oligoarthritis affecting mainly the shoulders, elbows, knees and ankles, while sacroileitis was found in $29 \%$ ( $80 \%$ unilateral), demonstrating some similarity to other enteroarthritides. Some autoimmune rheumatic

\section{Learning points}

- Coeliac disease in adults may present with a musculoskeletal complication in up to $20 \%$ of cases.

- Coeliac disease may rarely cause an oligoarthritis affecting larger joints that usually responds to a gluten-free diet.

- Adult patients with coeliac disease may have a normal bowel habit.

- Though rare, coeliac disease can present in the elderly, an underlying malignancy being the most likely differential diagnosis.

- Coeliac disease is a cause of an unexplained anaemia with multiple deficiencies. The serum folate is a sensitive screening test.

conditions also appear to be associated with coeliac disease, ${ }^{10}$ the most common being primary Sjogren's syndrome.

\section{Final diagnosis}

Coeliac disease complicated by osteomalacia, osteoporosis, and oligoarthritis.

1 Corazzo GR, Gasbarrini G. Coeliac disease in adults. Bailliere's Clin Gastroenterol 1995;9:329-50.

2 Corazzo GR, Frisoni M, Treggiari EA, et al. Clinical features of adult coeliac disease in Italy. In: Mearin ML, Mulder CJJ, eds. Coeliac disease: 40 years gluten free. Dordrecht: Kluwer Academic Publishers, 1991.

3 Bourne JT, Kumar P, Huskisson EC, et al. Arthritis and coeliac disease. Ann Rheum Dis 1985;44:592-8.

4 Trier JS. Celiac sprue and refractory sprue. In: Feldman M, Scharschmidt BF, Sleisenger MH, eds. Gastrointestinal and Scharschmidt $\mathrm{BF}$, Sleisenger MH, eds. Gastrointe
liver disease. Philadelphia: WB Saunders, 1998.

5 Caraceni MP, Molteni N, Bardella MT, et al. Bone mineral Caraceni MP, Molteni N, Bardella MT, et al. Bone mineral
metabolism in adult coeliac disease. Am $₹$ Gastroenterol metabolism in

6 Vialimarrson T, Lofman D, Toss G, et al. Reversal of osteopenia with diet in adult coeliac disease. Gut 1996;38:322-7. 7 Adelizzi RA, Pecora AA, Chieza JC. Celiac disease: case report with an associated arthropathy. Am $\mathcal{F}$ Gastroenterol 1982;77:481-5.

8 Borg AA, Dawes PT, Swan CHJ, et al. Persistent monoarthritis and occult coeliac disease. Postgrad Med 7 1994;70:51-3.

9 Lubrano E, Ciacci C, Ames PRJ, et al. The arthritis of coeliac disease: prevalence and pattern in 200 adult patients. $\mathrm{Br}$ f Rheumatol 1996;35:1314-18.

10 Collin P, Korpela M, Hallstrom O, et al. Rheumatic complaints as a presenting symptom in patients with coeliac disease. Scand f Rhematol 1992;21:20-3. 


\title{
A reversible cause of acute renal failure
}

\author{
S Mehandru, A Goel
}

Department of

Medicine, New York

University (VA

Program), New York,

USA

S Mehandru

\section{Department of \\ Medicine, Lady \\ Hardinge Medical \\ College, New Delhi, \\ India \\ A Goel}

Correspondence to: Dr Saurabh Mehandru, 18 Stuyvesant Oval, Apt 6E, New York, NY 10009, USA saurabh_13@hotmail.com

Submitted

16 November 1999

Accepted 6 March 2000

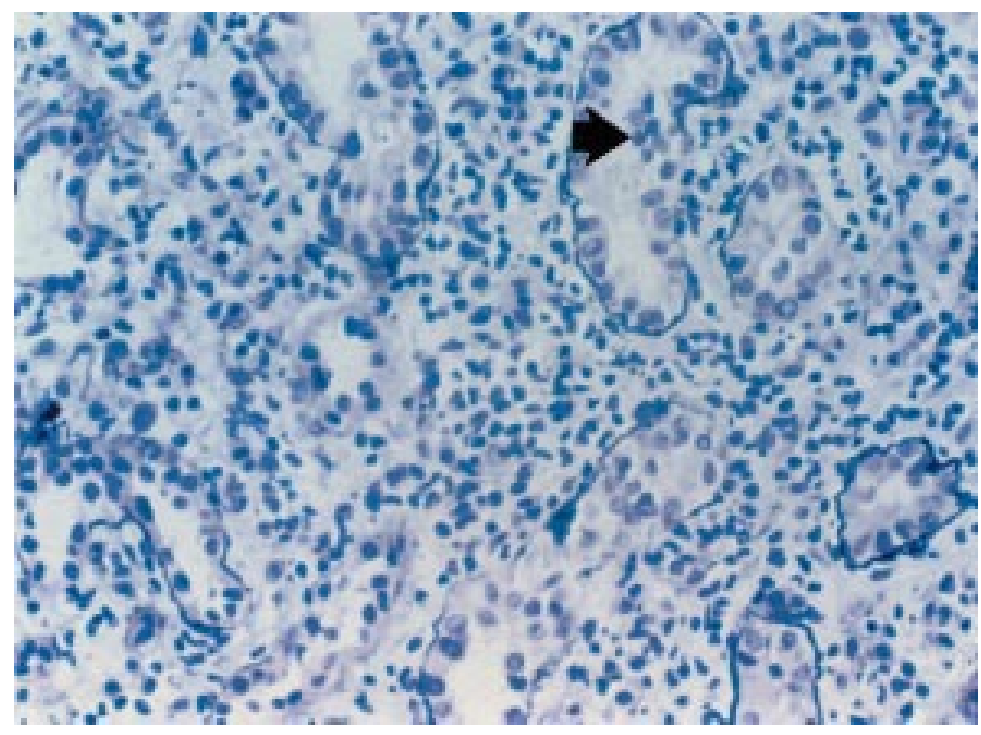

Figure 1 Kidney biopsy: showing interstitial, predominantly mononuclear inflammatory infiltrate comprised mainly of lymphocytes and plasma cells and areas of tubular invasion by the lymphocytes denoting tubulitis (arrow).

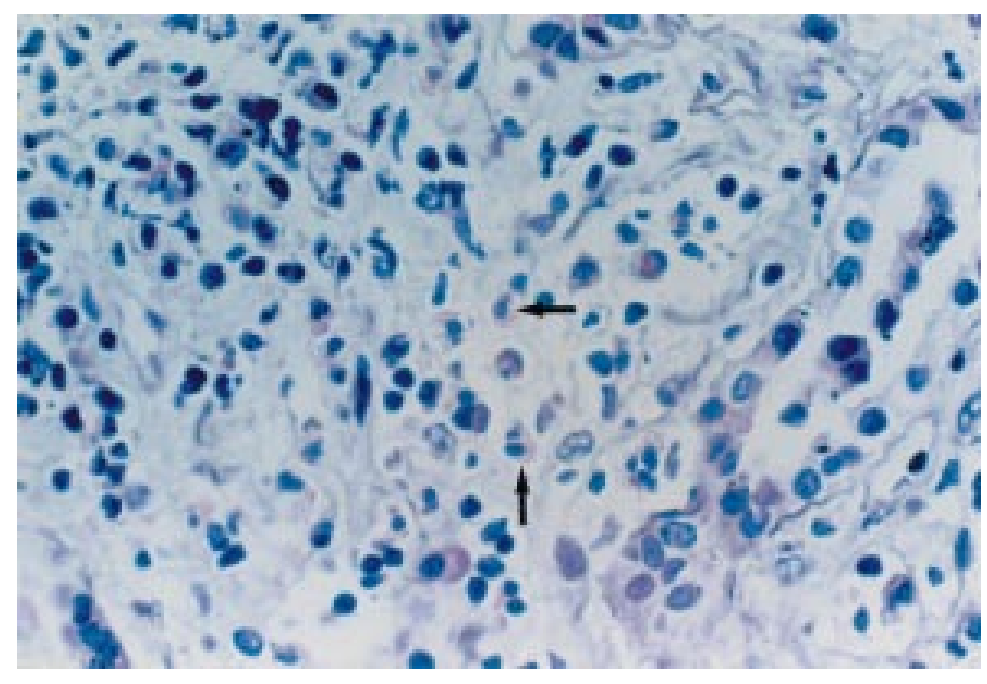

Figure 2 Kidney biopsy: showing a few eosinophylic leucocytes present in the interstitium (arrows).

A 63 year old homeless man presented to the Bellevue Hospital Center in New York with a one month history of cough with expectoration, fever, and weight loss. One week before presentation, the patient had also developed moptysis. Chest radiography demonstrated total destruction of the left upper lobe parenchyma. The patient's sputum was teeming with acid fast bacilli (AFB). He was started on rifampicin $450 \mathrm{mg}$ each day, isoniazid 300 mg each day, pyrizinamide $750 \mathrm{mg}$ twice a day, and ethambutol $800 \mathrm{mg}$ each day in consistence with the diagnosis of extensive pulmonary tuberculosis. He tested HIV negative. The laboratory results were significant for a

$$
\text { callon }
$$
cant for an ESR of $80 \mathrm{~mm} /$ hour and $14 \%$ eosinophils in the peripheral blood. The antitubercular medications were discontinued, however, the deterioration in renal function continued and the creatinine concentrations reached $795.6 \mu \mathrm{mol} / 1$. The patient was dialysed at this point.

With no further improvement in the renal function, a kidney biopsy was performed. Based on the results, the patient was started on prednisone $60 \mathrm{mg}$ each day. Modified antitubercular treatment was reinstated in the form of isoniazid $300 \mathrm{mg}$ each day, ciprofloxacin 750 mg twice a day, and pyrizinamide $750 \mathrm{mg}$ twice a day. Within the next two weeks, the renal function started improving. Over the next three weeks, prednisone was tapered. The renal function continued to improve and returned to baseline subsequently.

\section{Questions}

(1) What are the findings on the kidney biopsy?

(2) What is the diagnosis?

(3) What are the common aetiological factors responsible for this condition?

\section{Answers}

Q1: What are the findings on the kidney biopsy?

The given biopsy slides show an interstitial, predominantly mononuclear inflammatory infiltrate comprised mainly of lymphocytes and plasma cells (fig1). A few eosinophylic leucocytes are also present in the interstitium (fig 2). Of significance is the marked interstitial oedema (fig 3). In addition, there were areas of tubular invasion by the lymphocytes denoting tubulitis (fig 1). The glomerulus appears to be normal (fig 4). 


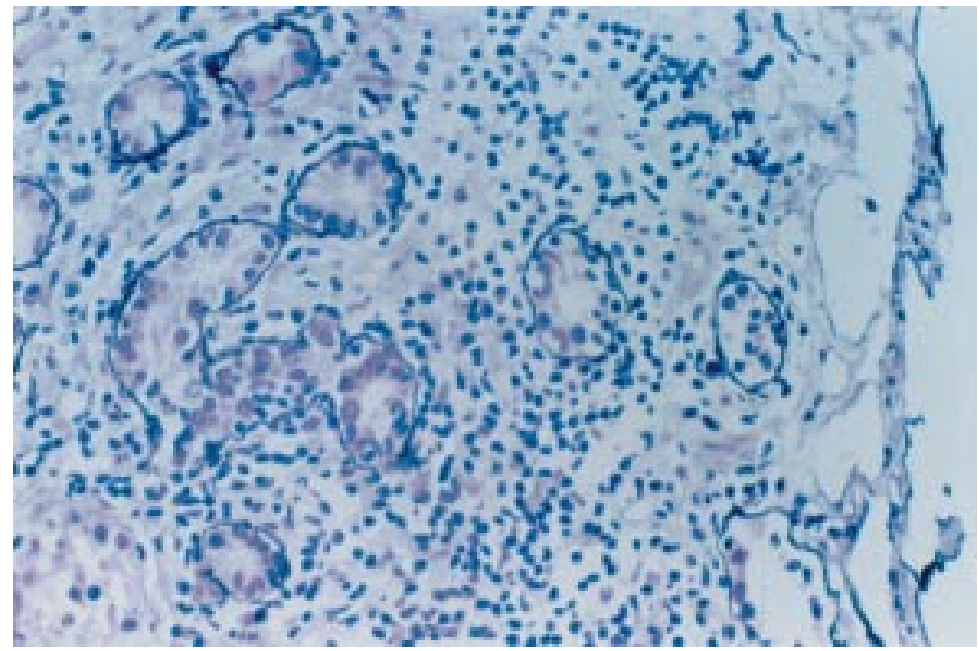

Figure 3 Kidney biopsy: showing marked interstitial oedema.

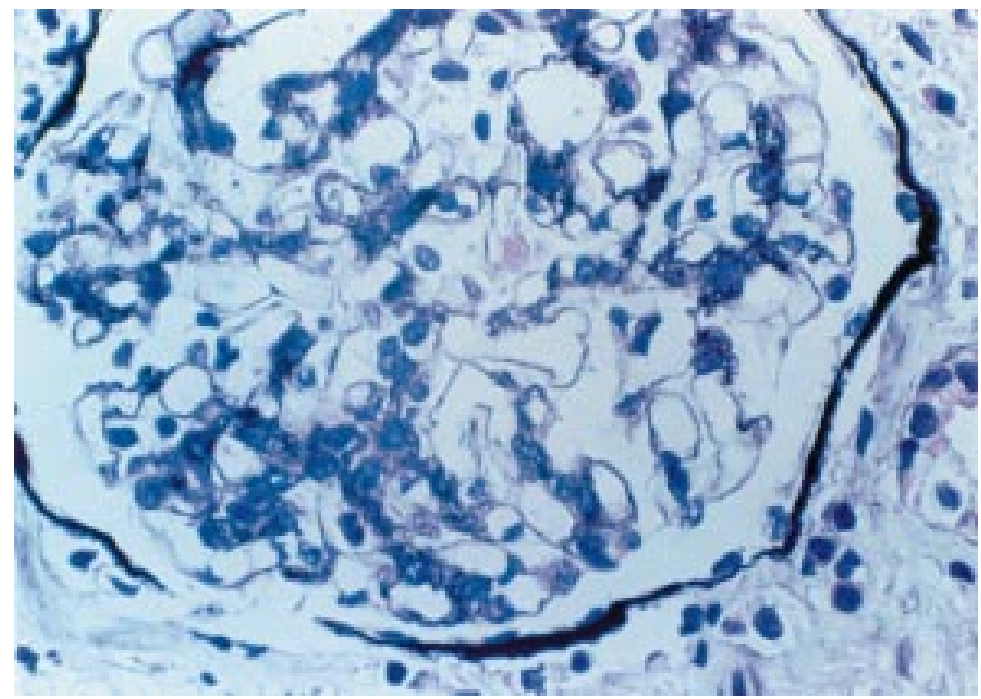

Figure 4 Kidney biopsy: showing an apparently normal glomerulus.

Q2: What is the diagnosis?

The diagnosis is acute interstitial nephritis (AIN). The likely aetiological factor is the antitubercular drug therapy, the most probable cause being rifampicin.

\section{Q3: What are the common aetiological factors responsible for this condition?}

The causes of AIN can be classified into five general categories: drug hypersensitivity reactions, infections, immune mediated diseases, glomerular diseases, and idiopathic. Drug hypersensitivity has become the most common aetiological factor responsible for the condition, the prototype agent being methicillin. ${ }^{1}$ Other classes include non-steroidal anti-inflammatory agents (NSAIDs); antibiotics such as $\beta$-lactams, sulphonamides, tetracycline, vancomycin, indinavir, interferon alfa, and rifampicin. Rifampicin has been implicated as a cause particularly when it is taken discontinuously. ${ }^{2}$ Some of the many other drugs implicated in causing AIN are diuretics, phenytoin, cemitidine, allopurinol, and aspirin. Infections are becoming less common a cause of $\mathrm{AIN}^{2}$ particularly in areas where there is ready access to antibiotics. The reported causative agents include bacteria such as streptococci and staphylococci; viruses such as cytomegalovirus, Epstein-Barr virus and HIV; toxoplasma; mycoplasma; rickettsiae; leishmaniae and spirochaetes such as leptospira and Treponema pallidum. AIN can also occur with the autoimmune diseases such as systemic lupus erythematosus, Sjogren's syndrome, essential cryoglobulinaemia, and primary biliary cirrhosis. The various glomerulonephrites can have interstitial nephritis as the accompanying component. AIN can also be idiopathic, for example, as a defining entity of the tubulointerstitial nephritis-uveitis syndrome. ${ }^{3}$

\section{Discussion}

AIN is becoming an important cause of acute but reversible renal failure. Drug hypersensitivity, as discussed above, has become the most common aetiological factor responsible for the condition. The typical presentation of AIN is that of abrupt onset of renal dysfunction in a hospitalised patient with progressive rise of the serum creatinine. The triad of a rash, fever and eosinophyluria, though classical, may be found in only about $30 \%$ of the cases, ${ }^{4}$ more commonly so with the drug hypersensitivity reactions. Renal biopsy remains the "gold standard" for establishing the diagnosis. It should be considered if the serum creatinine continues to rise even after discontinuation of the offending drugs and immunosuppressive therapy is contemplated, or if a drug critical to the patient's treatment is suspected to be the cause of AIN. ${ }^{2}$ The urine analysis in AIN typically displays leucocytes, leucocyte casts, and occasionally red blood cells. ${ }^{5}$ Red blood cell casts are found very rarely. Eosinophiluria detectable by the Wright's stain or Hansel's stain was considered to be diagnostic for AIN,${ }^{6}$ but it is increasingly falling out of favour in establishing the diagnosis not only because the stains may not be readily available but also because the finding may have a sensitivity of about $40 \%$ and a specificity of about $72 \%$ only. ${ }^{7}$ Proteinuria in AIN is typically less than 1 $\mathrm{g} /$ day, the urine output is usually maintained and there may be isosthenuria. Light microscopy usually shows an inflammatory cell infiltrate along with interstitial oedema. Plasma cells or eosinophils may be seen in the interstitium. Among the lymphocytes, the CD4+ cells predominate. Granulomas can be seen, particularly with the drug hypersensitivity reactions. In NSAID induced AIN, the changes may resemble those seen in minimal change disease with the effacement of the epithelial foot processes on electron microscopy. ${ }^{2}$ The mainstay of treatment is supportive and withdrawal of the offending drug. Early diagnosis and discontinuation of the drug are critical in the recovery of the renal function. In cases where the drug withdrawal does not lead to a recovery of the renal function, pharmacotherapy must be considered. Prednisolone is the most commonly prescribed drug, in a dose of $1 \mathrm{mg} / \mathrm{kg} / \mathrm{day}$, given orally. Adjunct therapy with cyclophophosphamide has been considered if trials of steroid therapy yield a poor response, ${ }^{8}$ there is however, little clinical 
evidence to support the efficacy of cyclophosphamide in this disorder and the drug is probably required only very rarely. Plasmapheresis may be considered in addition to prednisolone and cyclophosphamide in the very rare patient in whom the interstitial nephritis is demonstrated to be due to antitubular basement antibodies, as suggested by the linear deposition of IgG along the tubular basement membranes on immunofluorescent microscopy. However, again there is no proof that this modality is effective in the treatment of acute interstitial nephritis. Immunosuppressive therapy is unlikely to be effective in patients who have pre-existing advanced chronic renal disease on their renal biopsy and little evidence of acute inflammation and should be withheld in these cases.

AIN thus remains an important cause of potentially reversible renal failure that needs a high index of suspicion for the diagnosis and an early withdrawal of the offending drug for recovery of renal function.

\section{Final diagnosis}

Acute interstitial nephritis.

1 Baldwin DS, Levine BB, McCluskey RT, et al. Renal failure and interstitial nephritis due to penicillin and methicillin. $N$ Engl F Med 1968;279:1245.

2 Michel DM, Kelly CJ. Acute interstitial nephritis. $\mathcal{A}$ Am Soc Nephrol 1998;9:506-15.

3 Steinman TI, Silva P. Acute interstitial nephritis and iritis. Renal-ocular syndrome. Am f Med 1984;77:189-91.

4 Eapen SS, Hall PM. Acute tubulointerstitial nephritis. Cleve Clin ₹ Med 1992;59:27-32.

5 Ten RM, Torres VE, Milliner DS, et al. Acute interstitial nephritis: immunologic and clinical aspects. Mayo Clin Proc 1988;63:921-30.

6 Nolan CR, Anger MS, Kelleher SP. Eosinophiluria-a new method of detection and definition of the clinical spectrum. M Engl f Med 1986;315:1516-19.

7 Ruffing KA, Hoppes P, Blend D, et al. Eosinophils in urine revisited. Clin Nephrol 1994;41:163-6.

8 Neilson EG. Pathogenesis and therapy of interstitial nephritis. Kidney Int. 1989;35:1257-70. 